\title{
Effect of Durian Peel Ash Added in Zinc Oxide/Reduced Graphene Oxide Composites Used as a Chemical Sensor for Hydrazine Detection
}

\author{
Santi Rattanaveeranon ${ }^{1 *}$, Knavoot Jiamwattanapong1, Nattaphorn Jandee ${ }^{2}$ \\ ${ }^{1}$ Faculty of Liberal Arts, Rajamangala University of Technology Rattanakosin (RMUTR), Nakhon Pathom, Thailand \\ ${ }^{2}$ Faculty of Science and Technology, Rajamangala University of Technology Rattanakosin (RMUTR), Nakhon Pathom, Thailand \\ Email: *santi.r@rmutr.ac.th
}

How to cite this paper: Rattanaveeranon, S., Jiamwattanapong, $\mathrm{K}$. and Jandee, N. (2021) Effect of Durian Peel Ash Added in Zinc Oxide/Reduced Graphene Oxide Composites Used as a Chemical Sensor for Hydrazine Detection. Materials Sciences and Applications, 12, 111-120.

https://doi.org/10.4236/msa.2021.122007

Received: January 21, 2021

Accepted: February 20, 2021

Published: February 23, 2021

Copyright $\odot 2021$ by author(s) and Scientific Research Publishing Inc. This work is licensed under the Creative Commons Attribution International License (CC BY 4.0).

http://creativecommons.org/licenses/by/4.0/

\begin{abstract}
As the hydrazine is toxic, the methods to detect hydrazine at low concentrations are essential in scientific research. This preliminary study reported on how to increase the efficiency of $\mathrm{ZnO} /$ reduced graphene oxide (rGO) by adding durian peel ash (DPA) and using three-electrode method. The $\mathrm{ZnO} / \mathrm{rGO}$ composites were prepared using chemical reaction of graphene oxide (GO) with zinc chloride. The rGO was prepared by the chemical reduction of GO using hydrazine. The properties of the samples were investigated using scanning electron microscopy, atomic force microscopy, X-ray diffraction, and Potentiostat/Galvanostat. The results showed that the optimal condition for the composite material was $70 \% \mathrm{DPA}: 30 \% \mathrm{ZnO} / \mathrm{rGO}$ with the sensitivity of 222.92 $\mathrm{mA} / \mathrm{mM} \cdot \mathrm{cm}^{2}$ and the current density up to $116.50 \pm 0.95 \mathrm{~A} / \mathrm{g}$. The relationship between the current and the hydrazine concentration was $\mathrm{I}(\mu \mathrm{A})=48.69+$ 21.91C ( $\mathrm{mM}$ ) with $\mathrm{R}^{2}$ of 0.9870 . The minimum concentration of hydrazine solution that the modified electrode can measure was $0.125 \mathrm{mM}$. The DPA powder can then be used to enhance the hydrazine detection efficiency at low concentrations.
\end{abstract}

\section{Keywords}

Durian Peel Ash, Zinc Oxide, Reduced Graphene Oxide, Chemical Sensor

\section{Introduction}

Graphene is a single-layer sheet composed of $\mathrm{sp}^{2}$ hybridized atoms [1]. Due to its significant potential for fundamental studies and technological applications, it 
has been considerably investigated for several years [2]. Graphene, theoretically, has a large surface area of $2600 \mathrm{~m}^{2} / \mathrm{g}$ enabling it as a suitable material for various biochemical applications [3].

Conducting polymers were used as the active area on glassy carbon electrode (GCE) such as poly(3,4-ethylenedioxythiophene) (PEDOT). PEDOT is a relatively new and well known p-conjugated conducting polymer of the polythiophene class so it has received much attention due to its high electrical conductivity, moderate band gap and excellent environmental stability [4]. The unique properties of PEDOT can be employed in several fields: chemical and biochemical sensors, antistatic coatings, electrically switchable windows and polymer lightemitting diodes [5]. However, metal hexacyanoferrates (MHCFs) such as NdHCF [6], AgHCF [7], SnHCF [8], CoHCF [9], NiHCF [10], CuHCF [11], etc., have also gained much attention because of their particular properties and potential applications [12]. In case of PEDOT, the sensitivity of AgHCF-f-MECNT/PEDOT/GCE was $62.169 \mu \mathrm{A} \cdot \mu \mathrm{M}^{-1} \cdot \mathrm{cm}^{-2}$ and the linear range spans the catechin concentration of 1 to $50 \mathrm{mM}$ with a correlation coefficient of 0.9819 and the detection limit was $10 \mathrm{M}[5]$.

Hydrazine and its derivatives are well-known compounds due to their extensive industrial applications [13]. In spite of their extensive applications, hydrazine and its derivatives are extremely toxic and carcinogenic [14]. Many analytical methods such as high-performance liquid chromatography [15], spectrophotometric method [16], flow injection analysis [17], gas chromatography-mass spectrometry and potentiometry [18] have been used for the detection of hydrazine concentration. However, most of these methods involve time-employing schemes. The electrochemical technique has an advantage as it is simple, fast, sensitive and selective. Nonetheless, naked electrodes suffer from serious disadvantage such as high over potential and modified electrode applications have been examined to overcome the defects of bare electrodes. Even though diverse modified electrodes reported electrochemical determination of hydrazine, only very few offered trace level detection of hydrazine and henceforth fabrication of highly sensitive modified electrodes for trace level determination of hydrazine are greatly desirable. This research aims to improve the method to measure hydrazine at low concentrations by adding durian peel ash (DPA) in zinc oxide/reduced graphene oxide composites.

\section{Experimental Procedure}

\subsection{Graphene Oxide Synthesis}

Graphene oxide was synthesized by Hummers method, starting with natural graphite ( $3 \mathrm{~g}, 20 \mu \mathrm{m}, 99.99 \%$ purity, from Lianyungang Jinli Carbon). The remaining graphite was heated at $300^{\circ} \mathrm{C}$ in oven for $2 \mathrm{~h}$. to remove the water content. The dried solid was then mixed with $1.5 \mathrm{~g}$ of $\mathrm{NaNO}_{3}$ and $9 \mathrm{~g}$ of $\mathrm{KMnO}_{4}$, by slow adding $69 \mathrm{ml}$ concentrated sulfuric acid to the mixture in a $1000 \mathrm{ml}$ beaker under cooling and stirred at room temperature for $30 \mathrm{~min}$. The solution would 
be diluted using $420 \mathrm{ml}$ of water so that the temperature of the system went down to $50^{\circ} \mathrm{C}$. Slowly added $3 \mathrm{ml}$ of $30 \% \mathrm{H}_{2} \mathrm{O}_{2}$ to the beaker while stirring. The suspension was stirred at certain temperature and time and the solution was washed using deionized water with vacuum filtration. Finally, graphene oxide (GO) precipitates were dissolved in $30 \mathrm{ml}$ of distilled water.

\subsection{Synthesis of ZnO on Reduced Graphene Oxide Hybrid Nanoparticle Materials}

The GO was dispersed in the water to form a $30 \mathrm{ml}$ of $0.2 \mathrm{mg} \cdot \mathrm{ml}^{-1}$ by ultrasonication for $20 \mathrm{~min}$. Added $0.2 \mathrm{M}$ of $\mathrm{ZnCl}_{2}$ into the GO dispersion, then added $\mathrm{NaOH} 0.1 \mathrm{M}, 30 \mathrm{ml}$. The microwave equipment was used for the synthesis, consuming the power of $420 \mathrm{~W}$ for $30 \mathrm{~s}$ and the sample was suspended for $20 \mathrm{~s}$ then repeated this procedure until $10 \mathrm{~min}$. Then adjusted the $\mathrm{pH}$ of the sample to be neutral. After ultrasonicating for $20 \mathrm{~min}$, the sample reacted for 2 hours at $80^{\circ} \mathrm{C}$; dark grey precipitates were obtained by vacuum filtration. The sample was then washed using DI-water until the $\mathrm{pH}$ was close to 7 . The precipitates were dried in tube furnace at $300^{\circ} \mathrm{C}$ for 2 hours in Ar-ambient air in order to form the zinc oxide $(\mathrm{ZnO})$ structure.

\subsection{Synthesis of Durian Peel Ash (DPA) Powder}

Raw durian peels, obtained generally from a market in Thailand, were used for the synthesis of DPA. Before carbonization, the durian peels were thoroughly cleansed using filtered water at least 2 times and the deionized water was used at the final stage. The durian peels were cut into thin slices of size $2 \mathrm{~cm} \times 1 \mathrm{~cm}$ and combusted in tube furnace at $650^{\circ} \mathrm{C}$ for 2 hours in Ar-ambient air. The DPA sheets were dry-milled using stainless ball mill for $12 \mathrm{~h}$. in $50 \mathrm{~mL}$ Teflon-bottle. Then the solid product was sieved using steel wire mesh. The ash product obtained was denoted for the DPA powder.

\subsection{Spectroscopic Measurement}

Transmission electron microscope (TEM, JEOL 1200) and field emission scanning microscope (FESEM, Hitachi, s-4700) were used to investigate the morphology of the prepared rGO, $\mathrm{ZnO} / \mathrm{rGO}$ and DPA composites. The GO, rGO $\mathrm{ZnO} / \mathrm{rGO}$ and $\mathrm{a} \% \mathrm{DPA}: \mathrm{b} \% \mathrm{ZnO} / \mathrm{rGO}$ composites were dropped on the substrates of glass slide and dried on the hotplate, then the product film was characterized by X-ray diffraction (XRD) on Bruker D8 Advance diffractometer with $\mathrm{Cu} \mathrm{K} \alpha$ radiation at a slowly scan rate of 0.021 degree/s to study the structural property.

\subsection{Electrochemical Measurement}

The electrochemical measurement was carried out in aqueous solution and the composite samples with apparent area of $1 \times 1 \mathrm{~cm}^{2}$ were synthesized and used as a working electrode, a Pt wire was used as a counter electrode, a saturated calomel electrode (SCE) was employed as a reference electrode. The loading amount 
of $\mathrm{GO}, \mathrm{rGO}$, and a\%DPA:b\% $\mathrm{ZnO} / \mathrm{rGO}$ composites were determined by the weight difference of the above electrode was approximately $1.5 \mathrm{mg}$. The stock solution was prepared from 0.1 to $1 \mathrm{mM}$. Amperometric detection VersaSTAT3 potentiostat with three-electrode cell was employed for electrochemical hydrazine detection.

\section{Results and Discussion}

\subsection{Morphology of Hybrid Materials}

There is homogeneous growing on the plane of rGO as seen from Figure 1(a), the SEM horizontal image, and Figure 1(b), the SEM vertical image. The microstructure and the dimension of the zinc oxide nanoparticles $(\mathrm{ZnO})$ were similar to those of the nanoparticles, as seen in Figure 1(c). The synthesis was in fact carried out in deoxygenated hi-purity water to minimize oxidation [18]. Figure 1(d), the top of the surface of DPA shows a high porosity of DPA and its bottom surface is shown in Figure 1(e). The average thickness of the as-prepared rGO, which measured from the height profile of the AFM image, is about $1.04 \mathrm{~nm}$, (approximately 3 layers of rGO) which corresponds to a few layers of rGO compared with the theoretical value of $0.34 \mathrm{~nm}$ for monolayer graphene, Figure 1(f). The morphology and the size distribution of $\mathrm{ZnO}$ nanoparticles were well-developed spherical shape at approximately $68.76 \pm 4.08 \mathrm{~nm}$, as seen in Figure $1(\mathrm{~g})$.

\subsection{Structural Property}

The X-ray diffraction (XRD) patterns of $\mathrm{rGO}, \mathrm{ZnO}, \mathrm{ZnO} / \mathrm{rGO}$ and DPA composites are shown in Figure 2 with the main peak of XRD of rGO found at 2 theta of about 25 degrees. The XRD pattern of $\mathrm{ZnO}$ nanoparticles is found at room temperature. After thermal treatment in ambient atmosphere it changes to $\mathrm{ZnO}$ / rGO powder. Additionally, the impurities could not be observed. All possible peaks of $\mathrm{ZnO}$ were observed indicating the polycrystalline nature of the product. The XRD pattern of $\mathrm{ZnO} / \mathrm{rGO}$ composite confirms the formation of $\mathrm{ZnO}$ nanoparticles through the characteristic sharp peaks at (100), (002), (101), (102), (110), (200), (103) and (121) planes of the wurtzite structure of $\mathrm{ZnO}$, which is consistent with the JPCDS 36-1451 database [19].

\subsection{Specific Surface Area}

The specific surface area (SSA) of the samples was shown in Table 1. and the kind of microstructure is determined by the selection of the substrate. The activated process and the preparation were controlled as in [20]. From Table 1, it is obvious that rGO can give very high SSA of $625.89 \mathrm{~m}^{2} / \mathrm{g}$ whereas the pure DPA holds the SSA of $309.70 \mathrm{~m}^{2} / \mathrm{g}$. When $\mathrm{ZnO}$ is attached to the surface of rGO, the SSA of $70 \% \mathrm{DPA}: 30 \% \mathrm{ZnO} / \mathrm{rGO}$ is decreased to $208.40 \mathrm{~m}^{2} / \mathrm{g}$. Babitha and coworkers explained that when $\mathrm{ZnO}$ NPs were developed in situ on the $\mathrm{rGO}$, and the size of $\mathrm{ZnO}$ nanocrystals was controlled, the SSA of $\mathrm{ZnO} / \mathrm{rGO}$ nanocomposite was decreased as $\mathrm{ZnO}$ nanocrystals could insert into rGO assembly [21]. 


\subsection{Electrochemical Properties}

Figure 3(a) shows the current density and the concentration of the samples: GO, $\mathrm{rGO}$ and $\mathrm{ZnO} / \mathrm{rGO}$. It can be seen that $\mathrm{ZnO} / \mathrm{rGO}$ gives the best performance, followed by $\mathrm{rGO}$ and GO has the lowest. The best response of $\mathrm{ZnO} / \mathrm{rGO}$ was obtained at $0.4 \mathrm{mM}$ of hydrazine concentration. Figure $3(\mathrm{~b})$ exhibits the current density when varying \%DPA with different scan rate of $0-0.1 \mathrm{~V} / \mathrm{s}$. As expected, the CVs of the a\%DPA:b\%ZnO/rGO mixed with Nafion-117 polymer modified
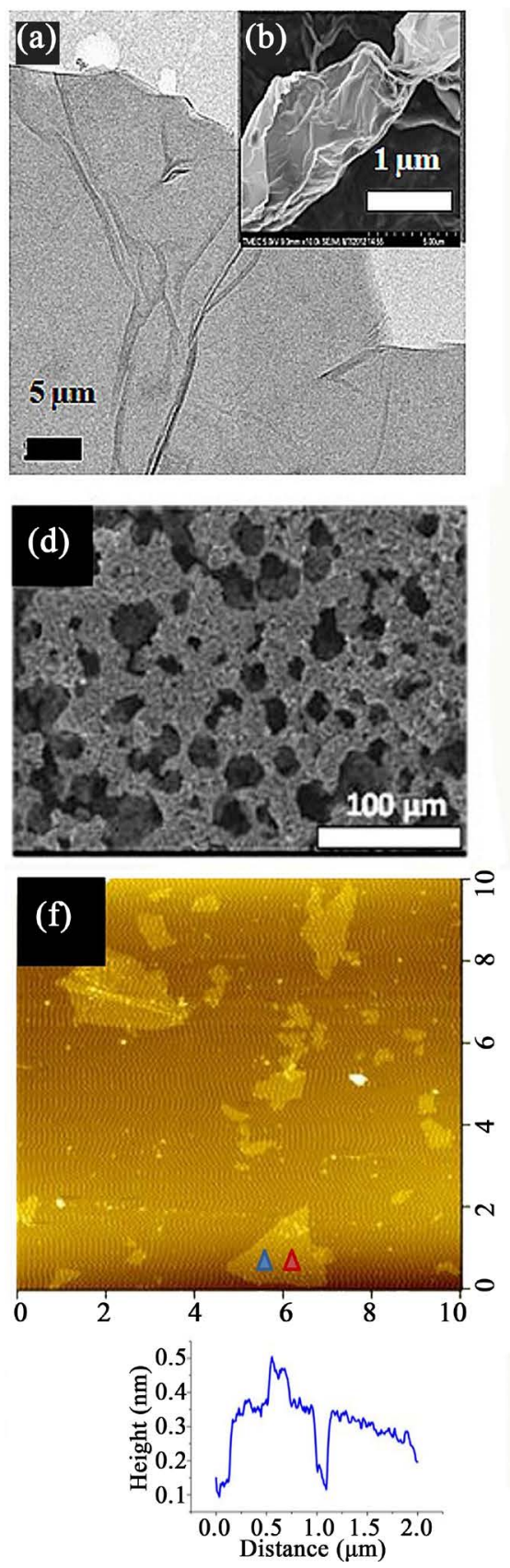
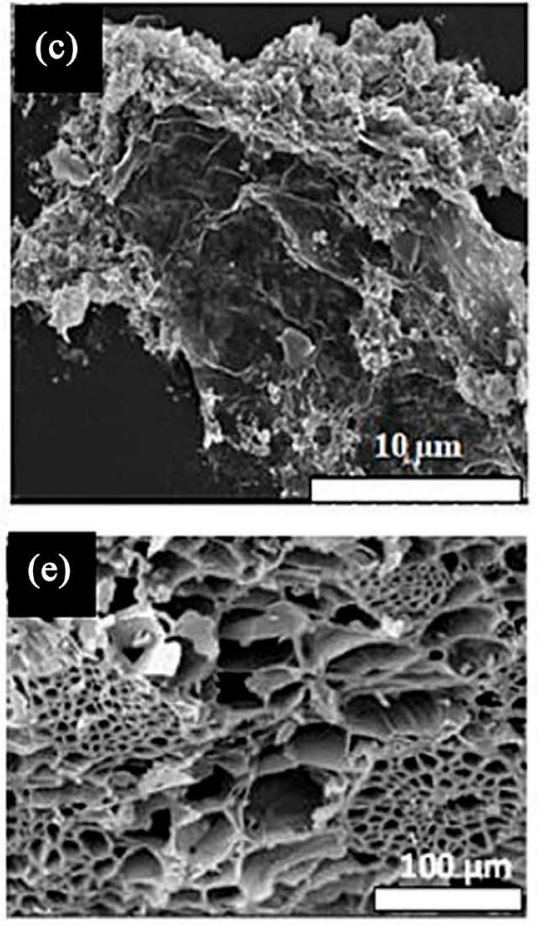

-

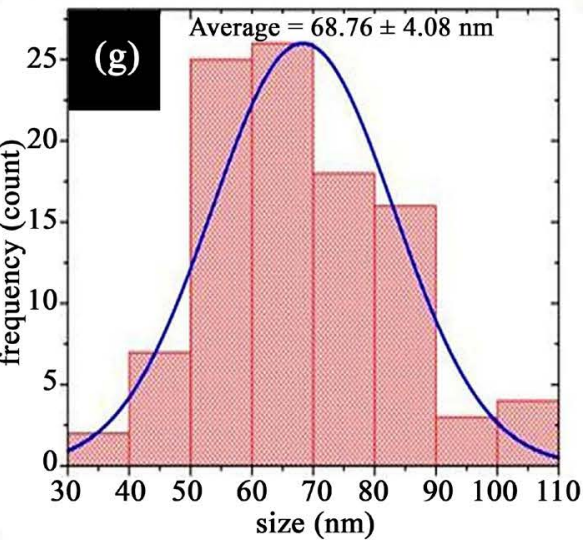

Figure 1. (a) SEM horizontal image of GO; (b) SEM vertical image of GO; (c) growth of $\mathrm{ZnO}$ nanoparticles upon rGO assembly; (d) top surface of DPA; (e) bottom surface of $\mathrm{DPA}$; (f) AFM image of rGO; (g) size distribution of $\mathrm{ZnO}$ nanoparticles. 


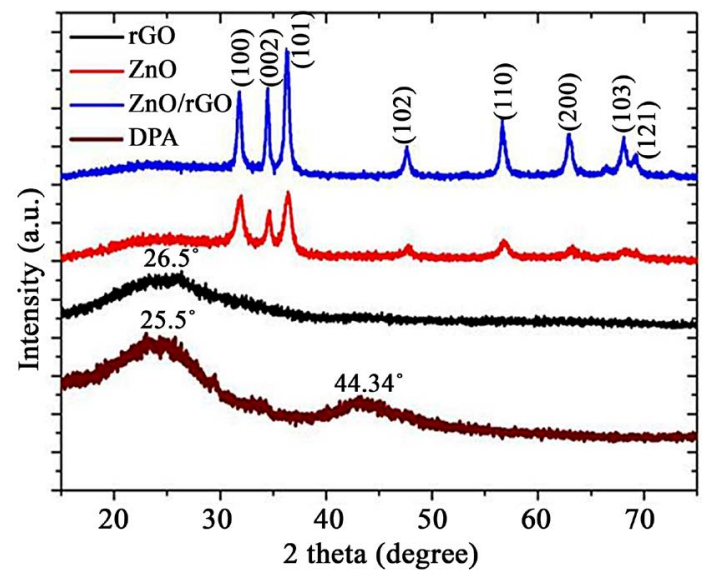

Figure 2. XRD diffractogram of $\mathrm{rGO}, \mathrm{ZnO}, \mathrm{ZnO} / \mathrm{rGO}$ and $\mathrm{DPA}$ composites.

Table 1. Specific surface area and pore size characteristics of the samples.

\begin{tabular}{ccccc}
\hline Sample & $\begin{array}{c}\text { SSA } \\
\left(\mathrm{m}^{2} / \mathrm{g}\right)\end{array}$ & $\begin{array}{c}\text { Total } \\
\text { pore volume } \\
(\mathrm{cc} / \mathrm{g})\end{array}$ & $\begin{array}{c}\text { Average } \\
\text { pore size } \\
(\mathrm{nm})\end{array}$ & $\begin{array}{c}\text { Current } \\
\text { Density } \\
(\mathrm{A} / \mathrm{g})\end{array}$ \\
\hline $\begin{array}{c}\text { Graphite (GH) } \\
\text { Annealing in air (AA) }\end{array}$ & 4.50 & 0.0755 & 76.60 & $5.12 \pm 0.25$ \\
rGO & 117.26 & 0.1570 & 4.37 & $15.33 \pm 0.22$ \\
ZnO/rGO & 625.89 & 0.9660 & 6.11 & $96.23 \pm 0.75$ \\
ZnO & 97.23 & 0.7620 & 3.54 & $105.69 \pm 1.75$ \\
$70 \% \mathrm{DPA}: 30 \% \mathrm{rGO}$ & 50.21 & 0.4498 & 56.90 & $12.36 \pm 2.45$ \\
$70 \% \mathrm{DPA}: 30 \% \mathrm{ZnO} / \mathrm{rGO}$ & 489.00 & 0.1680 & 131.40 & $102.33 \pm 1.22$ \\
$\mathrm{DPA}$ & 208.40 & 0.2760 & 2.69 & $116.50 \pm 0.95$ \\
& 309.70 & 0.1220 & 3.47 & $50.25 \pm 4.75$ \\
\hline
\end{tabular}

Remark: The graphite powder was treated at $300^{\circ} \mathrm{C}$ for $2 \mathrm{~h}$ in air atmosphere before analyzing.

electrode exhibit a single redox couple with the anodic peak at $+0.49 \mathrm{~V}$ and the cathodic peak at $+0.16 \mathrm{~V}$ versus $\mathrm{Ag} / \mathrm{AgCl} / \mathrm{KCl}$. Figure $3(\mathrm{c})$ shows the plot of $70 \% \mathrm{DPA}: 30 \% \mathrm{ZnO} / \mathrm{rGO}$ modified electrode signal of the anodic and maximum peak current vs. the scan rate. The linear relationship in the anodic current of $70 \% \mathrm{DPA}: 30 \% \mathrm{ZnO} / \mathrm{rGO}$ modified electrode according to the scan rate expressed that the film obtained specific characteristics of the surface controlled thin-layer electrochemical behavior. The corresponding linear regression equation was $I_{\max }$ $(\mathrm{mA})=17.76+0.17 \mathrm{~s}$, with $\mathrm{R}^{2}=0.9060$ where $\mathrm{s}$ is scan rate $(\mathrm{mV} / \mathrm{s})$. Figure $3(\mathrm{~d})$ shows the electrochemical activity of $70 \% \mathrm{DPA}: 30 \% \mathrm{ZnO} / \mathrm{rGO}$. From the shape of the impedance spectrum, the electron transfer kinetics and diffusion characteristics can be determined. The EIS was conducted in $0.4 \mathrm{mM}$ hydrazine monohydrate solution at the frequency range from $10 \mathrm{mHz}$ to $10 \mathrm{kHz}$. The straight line showing the relationship between the current and the concentration could be observed. The high frequency was ascribed to the double-layer capacitance (CDL) in parallel with Rct at the contact interface between electrode and electrolyte solution [22]. At low frequency, the impedance plot should theoretically 

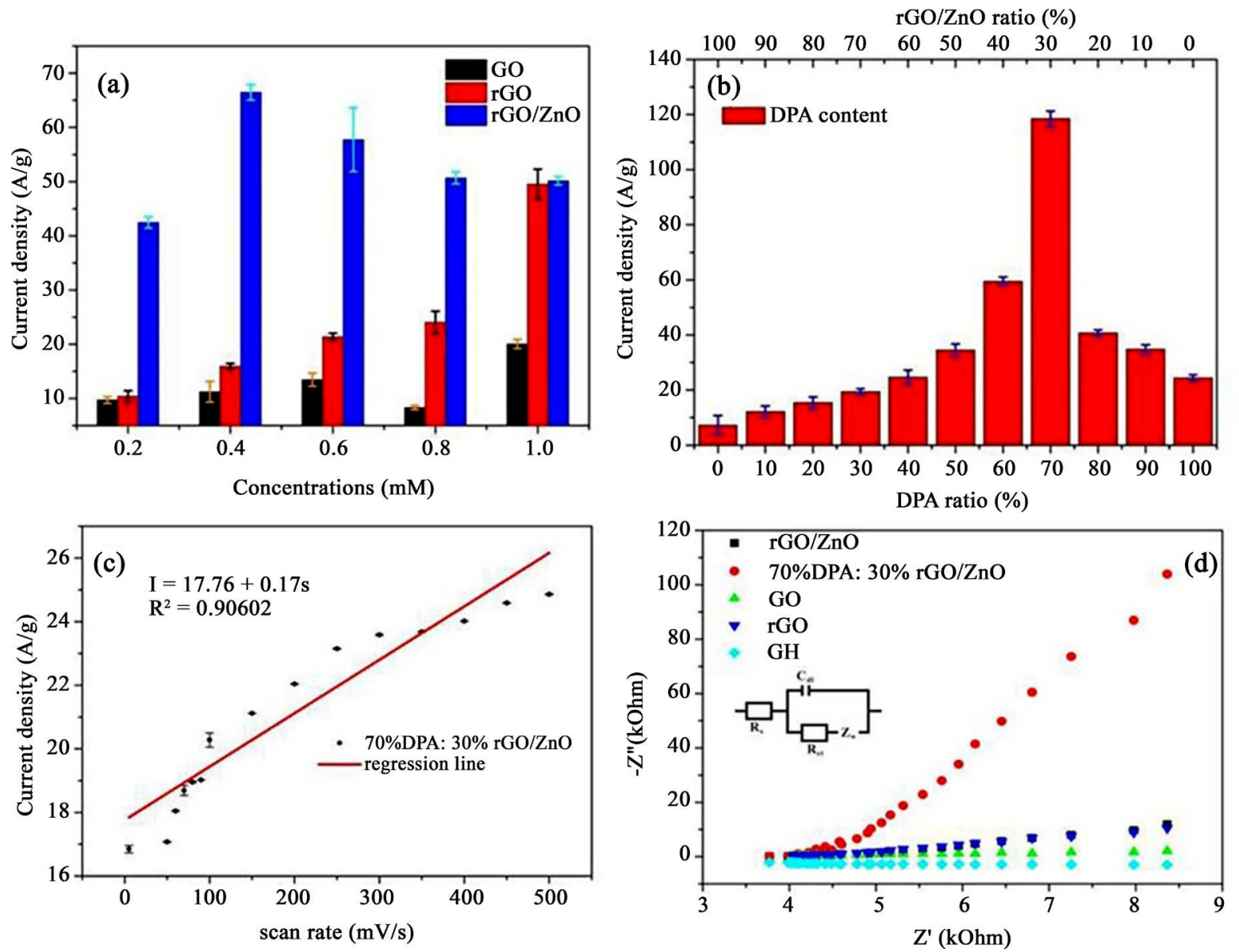

Figure 3. (a) Optimal condition for electrochemistry measurement of GO, rGO and $\mathrm{ZnO} / \mathrm{rGO}$ composites; (b) current density when varying DPA content in $\mathrm{ZnO} / \mathrm{rGO}$ composites; (c) regression line of 70\%DPA:30\%ZnO/rGO; (d) electrochemical impedance curves of the sample.

be a vertical line, which is parallel to the imaginary axis. As can be seen from Figure 3(d) and Table 1, the relationship between the imaginary part and the real part of impedance is quite linear; this result can be caused by the porosity of $70 \% \mathrm{DPA}: 30 \% \mathrm{ZnO} / \mathrm{rGO}$ is higher than that of other composites under the study which reflects that the solution resistance(Rs) decreased with the increasing of porosity [23].

Figure 4(a) shows the typical amperometric curve of $70 \% \mathrm{DPA}: 30 \% \mathrm{ZnO} / \mathrm{rGO}$ composite on successive step change of hydrazine concentration. Under the present condition, the steady state current has a linear relationship with the concentration of hydrazine in the range from 0.1 to $1 \mathrm{mM}$. It can be concluded that $70 \% \mathrm{DPA}: 30 \% \mathrm{ZnO} / \mathrm{rGO}$ composite is a good candidate for the fabrication of efficient hydrazine sensors. Figure 4(b) shows the positive linear relationship between the current and the concentration of hydrazine which is $\mathrm{I}(\mu \mathrm{A})=48.69+$ 21.91C (mM) with the association coefficient $\left(\mathrm{R}^{2}\right)$ of 0.9870 . The responsibility of the composite material was $222.92 \mathrm{~mA} / \mathrm{mM} \cdot \mathrm{cm}^{2}$. The minimum concentration of hydrazine solution that the modified electrode can measure was 0.125 $\mathrm{mM}$, obtained from $3 \times$ standard deviation/slope. 

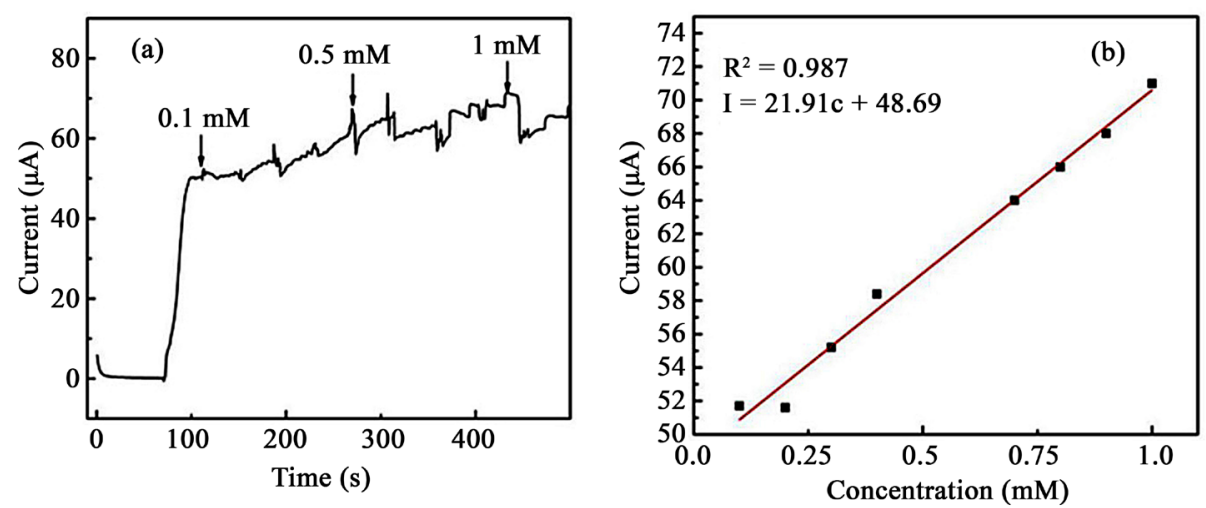

Figure 4. (a) Typical amperometric curve of 70\%DPA:30\%ZnO/rGO composite; (b) relationship between the current and the concentration of hydrazine of $70 \% \mathrm{DPA}: 30 \% \mathrm{ZnO} / \mathrm{rGO}$ composite.

\section{Conclusion}

The 70\%DPA:30\%ZnO/rGO/GCE hybrid film has been successfully electrodeposited on GCE. The conclusion from EIS results was that Nafion-117 greatly improved the conductance of the modified electrode. The $70 \% \mathrm{DPA}: 30 \% \mathrm{ZnO} / \mathrm{rGO}$ hybrid film modified electrode displays the linear response in the range of 0.1 to $1 \mathrm{mM}$ of $\mathrm{NH}_{2} \mathrm{NH}_{2} \cdot \mathrm{H}_{2} \mathrm{O}$ solution with the association coefficient(R-squared) of 0.9870 . The detection limit was found to be $0.125 \mathrm{mM}$. Use of DPA with the modified electrode method can improve the performance of hydrazine detection. To develop the probe for measuring hydrazine at low concentrations with adding DPA in $\mathrm{ZnO} / \mathrm{rGO}$ composite is certainly of interest for future research. Besides DPA, other bio ash such as sweet potato should be considered in order to obtain new methods used to measure hydrazine.

\section{Acknowledgements}

This research was financially supported by Rajamangala University of Technology Rattanakosin (RMUTR).The authors would like to thank the King Mongkut University of Technology Thonburi (KMUTT) for the arrangement of Potentiostat/Galvanostat for electrochemical measurement.

\section{Conflicts of Interest}

The authors declare no conflicts of interest regarding the publication of this paper.

\section{References}

[1] Novoselov, K.S., Geim, A.K., Morosov, S.V., Jiang, D., Katsnelson, M.I., Grigorieva, I.V., Dubonos, S.V. and Firsov, A.A. (2005) Electric Field Effect in Atomically Thin Carbon Films. Nature, 306, 666-669. https://doi.org/10.1126/science.1102896

[2] Geim, A.K. and Kim, P. (2008) Carbon Wonderland. Scientific American, 298, 90. https://doi.org/10.1038/scientificamerican0408-90

[3] Georgakilas, V., Otyepka, M., Bourlinos, A.B., Chandra, V., Kim, N., Kemp, K.C., Hobza, P., Zboril, R. and Kim, K.S. (2012) Functionalization of Graphene: Covalent 
Andnon-Covalent Approaches, Derivatives and Applications. Chemical Reviews, 112, 6156-6214. https://doi.org/10.1021/cr3000412

[4] Groenendaal, L.B., Jonas, F., Freitag, D., Pielartzik, H. and Reynolds, J.R. (2000) Poly(3,4-ethylenedioxythiophene) and It's Derivatives: Past, Present, and Future. Advanced Materials, 12, 481-494. https://doi.org/10.1002/(SICI)1521-4095(200004)12:7<481::AID-ADMA481>3.0.C $\mathrm{O} ; 2-\mathrm{C}$

[5] Matsumoto, K. (2007) High-Pressure Synthesis of Heterocycles Related to Bioactive Molecules. In: Bioactive Heterocycles II, Springer, Berlin, 1-42. https://doi.org/10.1007/7081_2007_058

[6] Sheng, Q.L., Yu, H. and Zheng, J.B. (2007) Sol-Gel Derived Carbon Ceramic Electrode for the Investigation of the Electrochemical Behavior and Electrocatalytic Activity of Neodymium Hexacyanoferrate. Electrochimica Acta, 52, 4506-4512. https://doi.org/10.1016/j.electacta.2006.12.047

[7] Noroozifar, M., Motlagh, M.K. and Taheri, A. (2009) Preparation of Silver Hexacyanoferrate Nanoparticles and Its Application for the Simultaneous Determination of Ascorbic Acid, Dopamine and Uric Acid. Talanta, 80, 1657-1664.

https://doi.org/10.1016/j.talanta.2009.10.005

[8] Hosseinzadeh, R., Sabzi, R.E. and Ghasemlu, K. (2009) Effect of Cetyltrimethyl Ammonium Bromide (CTAB) in Determination of Dopamine and Ascorbic Acid Using Carbon Paste Electrode Modified with Tin Hexacyanoferrate. Colloids and Surfaces B: Biointerfaces, 68, 213-217. https://doi.org/10.1016/j.colsurfb.2008.10.012

[9] Lin, K.C., Hong, C.P. and Chen, S.M. (2012) Electrocatalytic Oxidation of Alcohols, Sulfides and Hydrogen Peroxide Based on Hybrid Composite of Ruthenium Hexacyanoferrate and Multi-Walled Carbon Nanotubes. International Journal of Electrochemical Science, 7, 11426-11443.

[10] Zhou, D.M., Ju, H.X. and Chen, H.Y. (1996) Catalytic Oxidation of Dopamine at a Microdisk Platinum Electrode Modified by Electrodeposition of Nickel Hexacyanoferrate and Nafion. Journal of Electroanalytical Chemistry, 408, 219. https://doi.org/10.1016/0022-0728(95)04522-8

[11] Pauliukaite, R., Ghica, M.E. and Brett, C.M.A. (2005) A New Improved Sensor for Ascorbate Determination Copper Hexacyanoferrate Modified Carbon Film Electrodes. Analytical and Bioanalytical Chemistry, 381, 972-978.

https://doi.org/10.1007/s00216-004-2958-6

[12] Vittal, R., Gomathi, H. and Kim, K.J. (2006) Beneficial Role of Surfactants in Electrochemistry and in the Modification of Electrodes. Advances in Colloid and Interface Science, 119, 55-68. https://doi.org/10.1016/j.cis.2005.09.004

[13] Wang, Y., Wan, Y. and Zhang, D. (2010) Reduced Graphene Sheets Modified Glassy Carbon Electrode for Electrocatalytic Oxidation of Hydrazine in Alkaline Media. Electrochemistry Communications, 12, 187-190. https://doi.org/10.1016/j.elecom.2009.11.019

[14] Ahmar, H., Keshipour, S., Hosseini, H., Fakhari, A.R., Shaabani, A. and Bagheri, A. (2013) Electrocatalytic Oxidation of Hydrazine at Glassy Carbon Electrode Modified with Ethylenediamine Cellulose Immobilized Palladium Nanoparticles. Journal of Electroanalytical Chemistry, 690, 96-103. https://doi.org/10.1016/j.jelechem.2012.11.031

[15] Watt, G.W. and Chrisp, J.D. (1952) Spectrophotometric Method for Determination of Hydrazine. Journal of Analytical Chemistry, 24, 2006-2008. https://doi.org/10.1021/ac60072a044 
[16] Safavi, A. and Karimi, M.A. (2002) Flow Injection Chemiluminescence Determination of Hydrazine by Oxidation with Chlorinated Isocyanurates. Talanta, 16, 785-792. https://doi.org/10.1016/S0039-9140(02)00362-4

[17] Sun, M., Bai, L. and Liu, D.Q. (2009) A Generic Approach for the Determination of Trace Hydrazine in Drug Substances Using in Situderivatization-Headspace GC-MS. Journal of Pharmaceutical and Biomedical Analysis, 49, 529-533. https://doi.org/10.1016/j.jpba.2008.11.009

[18] Kołodziejczak-Radzimska, A. and Jesionowski, T. (2014) Zinc Oxide-From Synthesis to Application: A Review. Materials, 7, 2833-2881. https://doi.org/10.3390/ma7042833

[19] Zhang, X., Sui, Z., Xu, B., Yue, S., Luo, Y., Zhan, W. and Liu, B. (2011) Mechanically Strong and Highly Conductive Graphene Aerogel and Its Use as Electrodes for Electro Chemical Power Sources. Journal of Materials Chemistry, 21, 6494-6497. https://doi.org/10.1039/cljm10239g

[20] Zhu, Z., Li, A., Zhong, S., Liu, F. and Zhang, Q. (2008) Preparation and Characterization of Polymer-Based Spherical Activated Carbons with Tailored Pore Structure. Journal of Applied Polymer Science, 109, 1692-1698.

https://doi.org/10.1002/app.28304

[21] Babitha, K.B., Matilda, J.J., Mohamed, A.P. and Ananthakumar, S. (2015) Catalytically Engineered Reduced Graphene Oxide/ZnO Hybrid Nanocomposites for the Adsorption, Photoactivity and Selective Oil Pick-Up from Aqueous Media. RSC Advances, 5, 50223-50233. https://doi.org/10.1039/C5RA04850H

[22] Ribeiro, D.V., Souza, C.A.C. and Abrantes, J.C.C. (2015) Use of Electrochemical Impedance Spectroscopy (EIS) to Monitoring the Corrosion of Reinforced Concrete. Revista IBRACON de Estruturas e Materiais, 8, 529-546. https://doi.org/10.1590/S1983-41952015000400007

[23] Xu, A., Weng, Y. and Zhao, R. (2020) Permeability and Equivalent Circuit Model of Ionically Conductive Mortar Using Electrochemical Workstation. Materials, 13, 1179. https://doi.org/10.3390/ma13051179 